\title{
Neonatal COVID-19 infection: Initial experience from a tertiary care centre in Northern India
}

\author{
*Lokesh Tiwari ${ }^{1}$, Bhabesh Kant Chowdhry ${ }^{1}$, Amrita Banerjee ${ }^{1}$, Yankappa $\mathbf{N}^{1}$, Pradeep Kumar ${ }^{1}$, Arun \\ Prasad $^{1}$, Amit Kumar Sinha ${ }^{2}$, Binod Kumar Pati ${ }^{3}$, Hemali Heidi Sinha ${ }^{4}$
}

Sri Lanka Journal of Child Health, 2021; 50(3): 495-502

\begin{abstract}
Introduction: Data on COVID-19 transmission, manifestations and outcome for the neonatal population is scarce, particularly from developing country settings.
\end{abstract}

Objectives: To assess the transmission risk of SARS-CoV-2 in the mother-infant dyad and to describe the clinical profile of neonates born to COVID-19 positive mothers in a tertiary care centre in Northern India.

Method: An observational cohort study was conducted in the neonatal COVID-19 unit of All India Institute of Medical Sciences Patna, India. All neonates delivered by COVID-19 positive mothers at this hospital were admitted. During the pandemic, admissions were also allowed for out-born neonates positive for SARS-CoV-2. COVID-19 RT-PCR on nasopharyngeal swab of neonate at 24 and 48-72 hours was the primary outcome variable. Clinicolaboratory variables were collected during the hospital stay and follow up. An inferential analysis was done using SPSS version 22.0.

Results: Fifty-one out of 145 (142 delivered at our institute and 3 at other institutes) pregnant women tested positive for COVID-19. Two in-born neonates and two out-born neonates also tested positive. They had a significantly higher respiratory rate $(p=0.0006)$ as compared to COVID-19 negative new-borns. COVID-19 RT-PCR done on breast milk samples of twenty-five mothers, tested negative.

${ }^{1}$ Department of Paediatrics and Neonatology, ${ }^{2}$ Department of Paediatric Surgery, ${ }^{3}$ Department of Microbiology, ${ }^{4}$ Department of Obstetrics and Gynaecology, All India Institute of Medical Sciences, Patna, Bihar, India

*Correspondence: lokeshdoc@yahoo.com

iD https://orcid.org/0000-0002-2231-0152

(Received on 10 April 2021: Accepted after revision on 23 May 2021)

The authors declare that there are no conflicts of interest

Funding: None

Open Access Article published under the Creative

Commons Attribution CC-BY (cc) (i)
One inborn COVID-19 negative neonate born to a COVID-19 positive mother died of severe birth asphyxia due to meconium-stained liquor. One inborn COVID-19 negative neonate born to a COVID19 positive mother required 27 days of ventilator support due to meconium stained liquor. All other neonates, except two with risk factors, remained clinically stable requiring no specific treatment during hospital stay and follow-up.

Conclusions: With standard infection prevention and control practices, potential of infection transmission in neonates exists though they had less severe disease and needed no specific treatment except supportive care.

DOI: http://doi.org/10.4038/sljch.v50i3.9732

(Key words: COVID-19 in neonates, SARS-CoV-2, neonatal COVID-19 in developing countries, SARS-CoV-2 transmission in neonates)

\section{Introduction}

Severe acute respiratory syndrome coronavirus 2 (SARS-CoV-2) by now has affected more than 166 million population ${ }^{1}$. Data regarding vertical or horizontal transmission of corona virus disease 2019 (COVID-19) in neonates are scarce ${ }^{2-5}$. In a recent study from the United States of America, it was concluded that perinatal transmission of COVID-19 is unlikely, if correct hygienic precautions are taken ${ }^{6}$. However, this conclusion may not be valid for other settings and could be an underestimate of transmission potential of this novel virus as neonatal COVID-19 infection has been reported from UK, Italy and China ${ }^{2-5,7-9}$. Data on COVID-19 transmission, manifestations and outcome for the neonatal population is scarce, particularly from developing country settings ${ }^{4,8}$.

\section{Objectives}

To assess the transmission risk of SARS-CoV-2 in the mother-infant dyad and to describe the clinical profile of neonates born to COVID-19 positive mothers in a tertiary care centre in Northern India.

\section{Method}

Study design and participants: This is an observational study of the cohort of neonates admitted at neonatal COVID-19 unit of All India Institute of Medical Sciences Patna, India between 
$1^{\text {st }}$ June and $15^{\text {th }}$ December 2020 . Our tertiary care hospital is declared as a centre of excellence for COVID-19 care. All neonates delivered by COVID19 positive mothers at this hospital were eligible for admission. During the pandemic, admissions were also allowed for out-born neonates who were real time polymerase chain reaction (RT-PCR) positive for SARS-CoV-2. Before declaration of the hospital as a dedicated COVID-19 hospital, all pregnant women suspected with influenza-like illness or severe acute respiratory infection were tested for COVID-19 RT-PCR before delivery. In emergency situations the test was done as soon as possible but not necessarily before delivery. Once the hospital was labelled as a dedicated COVID-19 hospital, only COVID-19 positive pregnant women were allowed admission to this hospital. The demographic and clinical profile, laboratory tests, nasopharyngeal COVID-19 RT-PCR results and treatment variables of the newborns were collected from the case sheets. Two to four hourly clinical observations of temperature, heart rate (HR), respiratory rate (RR) and oxygen saturation $\left(\mathrm{SpO}_{2}\right)$, recorded in the first 48 hours of admission, were captured. Initial laboratory tests, including haemoglobin level, white blood cell (WBC) count, platelet count, C-reactive protein (CRP), prothrombin time (PT), activated partial thromboplastin time (aPTT), international normalizing ratio (INR) and serum ferritin were done as per clinical protocol and repeated as needed during the hospital stay. Results of COVID-19 RTPCR on nasopharyngeal swabs of neonates at 24 hours and 48-72 hours were taken as primary outcome variables and neonates with positive test at any point were compared with the group with negative result. They were screened for signs and symptoms suggestive of COVID-19 within the first 24 hours, at the time of discharge, and at two-week follow-up after discharge. List of variables for clinical screening included fever, cough, respiratory distress, feeding intolerance, altered bowel movements and change in behaviour or activity. On follow-up, parents of COVID-19 positive babies were given the choice for repeat COVID-19 RTPCR test. Mothers were also screened for symptoms of fever, cough, shortness of breath, sore throat, runny nose, anosmia, ageusia, myalgias, vomiting, and diarrhoea as per Indian Council of Medical Research (ICMR) clinical screening criteria. Due to restricted transport and clinical services during COVID-19 pandemic, primary follow-up was done through telemedicine with advice to visit hospital for un-resolved issues. Mothers were contacted again for any information missed during follow-up calls.

Clinical protocol: All neonates received standard and uniform treatment during the pandemic as per institutional neonatal COVID-19 protocol $^{10}$. Resuscitation of neonate was done in a physically separate adjacent room where a minimum number of personnel were allowed to attend the code, wearing a full set of personal protective equipment including N-95 mask. The umbilical cord was clamped promptly and skin to skin contact was avoided. Neonatal resuscitation followed standard resuscitation guidelines with safety precautions. If mother was COVID-19 positive, baby was separated from the mother and kept in designated neonatal COVID-19 isolation and nursed on expressed breast milk (EBM). Mothers were advised to maintain hand hygiene, use of face masks while expressing breast milk and breast hygiene just before and after manual expression of breast milk. The collected EBM was transported to the dedicated neonatal isolation unit through dedicated hospital staff. Visitors were not allowed inside the COVID-19 isolation area. Infected staff members were not allowed to handle the baby or mother. All COVID-19 positive mothers were kept at minimum distance of 6 feet from each other in a COVID-19 ward dedicated for mothers as per institutional protocol.

All the babies were tested for COVID-19 at 24 hours and after 48-72 hours. For stable babies, early discharge, home care, and telemedicine follow-up were advised ${ }^{11}$. If both results were negative, clinically stable babies were discharged home. If the newborn was COVID-19 positive and sick, care continued. Once the baby was discharged home, rooming-in was allowed maintaining distance of six feet if mother was still COVID-19 positive and preferably nursed on EBM with the assistance of a COVID-19 negative parent or family member. If that was not feasible, mother was advised to ensure washing her hands before breastfeeding and wearing a mask during breastfeeding. Mother and neonate dyad, still positive for COVID-19, were advised to repeat nasopharyngeal RT-PCR test for COVID-19 at 2 weeks.

COVID-19 RT-PCR testing protocol: Nasopharyngeal swab was collected, kept inside a vial containing viral transport media (Hi Media lab Pvt ltd) and sent under cold chain to in-house COVID-19 testing laboratory recognized by ICMR. RNA was extracted by silica column based technology (Qiagen viral RNA mini kit) and was subjected to one step multiplex RT-PCR in Biorad CFX 96 using PCR kits (TRUPCR SARS-COV-2 RT qPCRkit V- 2.0 (I), 3B BlackBio Biotech India Limited) approved by ICMR for detection of SARS$\mathrm{CoV}-2$. Result was interpreted as per manufacturer's instructions.

Ethical issues: Ethical clearance was granted by the Institutional Ethics Committee of the All India Institute of Medical Sciences, Patna, India under approval number AIIMS/Pat/IEC/2020/535. Informed written consent was obtained from the parents of the neonates enrolled in the study. 
Statistical analysis: An inferential analysis was done with results presented as proportions for categorical variables. For parametric continuous variables, mean and $95 \%$ confidence interval were calculated and compared using student t-test. For non-parametric continuous variables, median with interquartile range was compared using MannWhitney $U$ test. For categorical variables exact Fisher test was used. p value less than 0.05 was considered significant. Missed values were excluded from analysis. Data analysis was done using SPSS version 22.0 (IBM).

\section{Results}

A total of 142 pregnant women were admitted during the study period. Three COVID-19 positive mothers who delivered outside were also admitted. As part of universal screening, all of them were tested for COVID-19 by RT-PCR of nasopharyngeal swab and 51/145 (35.2\%) mothers were positive. Two out of 51 COVID-19 positive mothers had singleton non-viable product of conception, one had twin non-viable product of conception and one had a live twin delivery. Forty-seven inborn and 7 outborn babies were admitted to neonatal COVID-19 unit during the study period. Thus a total of 54 newborns were included in the study (Figure 1). All inborn neonates tested negative for SARS-CoV-2 on their first nasopharyngeal swab sample sent within
24 hours of life. Two neonates tested positive on repeat test during 48-72 hours of life. Two out-born neonates were referred to us with a positive COVID19 RT-PCR test done on the fifth day of life. Mother of the first out-born neonate tested positive before and after delivery while the father of the second outborn baby tested positive and mother tested negative on family screening. In both cases, no other household member tested positive. There was no domestic aid available during the lockdown period in both cases. Mode of delivery was lower segment caesarian section (LSCS) in 38 of 47 deliveries including both COVID-19 positive neonates. Three out-born neonates also had a history of delivery through LSCS. One out-born neonate born by normal vaginal delivery (NVD) tested positive. One COVID-19 positive mother had severe ARDS with multi-organ failure and succumbed to her illness though her baby tested negative for COVID-19 RTPCR throughout his NICU stay and during followup. Direct breast feeding was not allowed but expressed breast milk was given in all cases except one whose mother was too sick and hence received formula feed.

Figure 1 is the patient enrolment flow chart. A summary of the 54 babies included in this cohort is given in Tables 1 and 2 .

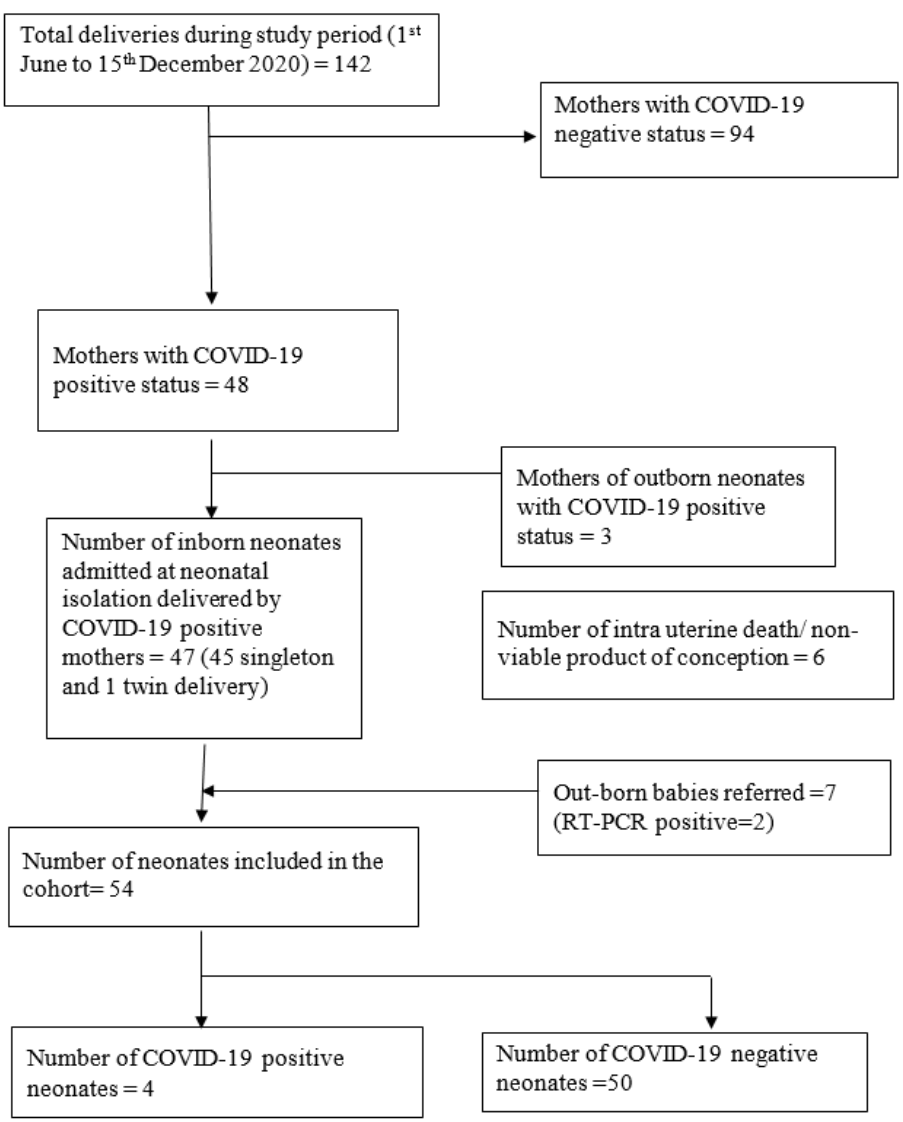

Figure 1: Patient enrolment flow chart 
Table 1: Comparative summary of neonates delivered by COVID-19 positive mothers

\begin{tabular}{|c|c|c|c|c|c|}
\hline Variable & $\begin{array}{c}\text { Covid-19 negative } \\
(\mathrm{n}=50)\end{array}$ & $\begin{array}{c}\text { Covid-19 positive } \\
\text { Case } 1 \\
\end{array}$ & $\begin{array}{c}\text { Covid-19 positive } \\
\text { Case } 2 \\
\end{array}$ & $\begin{array}{c}\text { Covid-19 positive } \\
\text { Case } 3 \\
\end{array}$ & $\begin{array}{c}\text { Covid-19 positive } \\
\text { Case } 4 \\
\end{array}$ \\
\hline Gestation (weeks) & $37+3 / 7(37-39+5 / 7)$ & 38 & $39+3 / 7$ & 38 & 36 \\
\hline Birth weight (kg) & $2.805(2.52-3.07)$ & 2.51 & 3.08 & 3.5 & 2.3 \\
\hline Mode of delivery & LSCS (38), NVD (12) & LSCS & LSCS & LSCS & NVD \\
\hline Apgar 1 minute & $8(8-9)$ & 8 & 9 & 9 & 9 \\
\hline Apgar 5 minutes & $9(9-10)$ & 8 & 9 & 9 & 10 \\
\hline $\begin{array}{l}\text { COVID-19 RT PCR } \\
\text { at } 24 \mathrm{hrs} \text { of birth }\end{array}$ & Negative & Negative & Negative & Not Known & Not known \\
\hline $\begin{array}{l}\text { COVID-19 RT PCR } \\
\text { at } 48-72 \text { hrs of birth }\end{array}$ & $\begin{array}{l}\text { Negative (46) } \\
\text { Not done (4) }\end{array}$ & Positive & Positive & Positive & Positive \\
\hline Cough & None & No & No & No & No \\
\hline Fever & 01 & No & No & No & No \\
\hline Shortness of breath & 08 & No & No & No & No \\
\hline Ventilatory support & NIV- 7, IV- 7 & No & No & No & No \\
\hline Inotropic support & 05 & No & No & No & No \\
\hline Comorbidities & $\begin{array}{l}\text { Congenital } \\
\text { hydronephrosis with } \\
\text { mesenteric cyst-1 } \\
\text { Delayed cry-5 } \\
\text { Early onset sepsis-1 } \\
\text { HIE :2 }\end{array}$ & No & No & $\begin{array}{c}\text { Neonatal } \\
\text { hyperbilirubinemia }\end{array}$ & $\begin{array}{c}\text { Imperforate anus } \\
\text { common cloaca }\end{array}$ \\
\hline Hospital stay (days) & $6(5-7)$ & 7 & 7 & 6 & 5 \\
\hline Status on discharge & Alive:47, Dead:03 & Alive \& stable & Alive \& stable & Alive \& stable & Alive \& stable \\
\hline 7 days follow up & All live babies stable & Stable & Stable & Stable & Stable \\
\hline 14 days follow up & All live babies stable & Stable & Stable & Stable & Stable \\
\hline
\end{tabular}

COVID-19: Corona virus disease 2019, LSCS: lower segment caesarean section, NVD: normal vaginal delivery, RT-PCR: reverse

transcriptase polymerase chain reaction, HIE: hypoxic ischaemic encephalopathy

Table 2: Comparative summary of clinical and laboratory observations of neonates

\begin{tabular}{|c|c|c|c|}
\hline Variable & Covid-19 negative $(n=50)$ & Covid-19 positive $(n=4)$ & P value \\
\hline $\begin{array}{l}\text { Temperature }\left({ }^{\circ} \mathrm{F}\right) \\
(97.7-99.3)\end{array}$ & $98.2(97.8-98.4)(\mathrm{n}=1186)$ & $98.2(97.9-98.4)(\mathrm{n}=100)$ & 0.1588 \\
\hline $\begin{array}{l}\text { Heart rate (per min) } \\
(110-160)\end{array}$ & $132(124-140)(\mathrm{n}=1205)$ & $130(126-138)(n=100)$ & 0.9139 \\
\hline $\begin{array}{l}\text { Respiratory rate (per min) } \\
(30-60)\end{array}$ & $44(42-46)(n=1204)$ & $44(42-48)(n=100)$ & 0.0006 \\
\hline $\begin{array}{l}\text { Pulse oxygen saturation (\%) } \\
(94-99 \%)\end{array}$ & $97(96-98)(n=1204)$ & $96(95-97.5)(\mathrm{n}=100)$ & 0.9024 \\
\hline $\begin{array}{l}\text { Haemoglobin }(g / d l) \\
(15-24)\end{array}$ & $17.6(14.3-20.6)(n=77)$ & $16.6(14.1-17.5)(\mathrm{n}=8)$ & 0.379 \\
\hline $\begin{array}{l}\text { White blood cell count }\left(\mathrm{x} 10^{3} / \mathrm{mm}^{3}\right) \\
(9.1-34)\end{array}$ & $16.38(12.505-21.5)(n=77)$ & $\begin{array}{c}13.395(12.175-17.87) \\
(\mathrm{n}=8)\end{array}$ & 0.3727 \\
\hline $\begin{array}{l}\text { Platelet count }\left(\times 10^{3} / \mathrm{mm}^{3}\right) \\
\left(0.84-4.78 \text { in } 1^{\text {st }} \text { week }\right)\end{array}$ & $2.45(1.735-2.87)(\mathrm{n}=77)$ & $3.08(2.6-3.31)(\mathrm{n}=8)$ & 0.0427 \\
\hline $\begin{array}{l}\text { C-reactive protein }(\mathrm{mg} / \mathrm{l}) \\
(0-5)\end{array}$ & $2.8(2.8-6)(n=61)$ & $6.69(3.84-9.7)(\mathrm{n}=7)$ & 0.9329 \\
\hline $\begin{array}{l}\text { Prothrombin time (seconds) } \\
(14.4-16.4)\end{array}$ & $17.03(15.48-19.12)(\mathrm{n}=52)$ & $15.24(14.51-16.97)(n=4)$ & 0.4672 \\
\hline $\begin{array}{l}\text { Activated partial thromboplastin time (seconds) } \\
(34.3-44.8)\end{array}$ & $33.42(27.6-38.38)(\mathrm{n}=52)$ & $31.76(30.87-36.44)(n=4)$ & 0.7354 \\
\hline $\begin{array}{l}\text { International normalized ratio } \\
(1.15-1.35)\end{array}$ & $1.31(1.16-1.48)(\mathrm{n}=52)$ & $1.14(1.08-1.28)(\mathrm{n}=4)$ & 0.46 \\
\hline $\begin{array}{l}\text { Serum ferritin }(n g / l) \\
(25-200)\end{array}$ & $304.22(207.24-515.51(\mathrm{n}=33)$ & $307.5(\mathrm{n}=2)$ & 0.7036 \\
\hline
\end{tabular}

All values in median followed by interquartile range (IQR); $n=$ number of observations

Among clinical variables recorded in the first 48 hours, COVID-19 positive neonates had a significantly higher respiratory rate $(p=0.0006)$ as compared to COVID-19 negative new-borns. All of them remained clinically stable requiring no specific treatment or additional hospital stay, attributable to COVID-19 positivity. All live babies remained stable at home and none reported COVID-19 related symptoms during follow-up. Case 1 tested negative on repeat RT-PCR done on the $15^{\text {th }}$ day of life; parents of case 2 did not opt for repeat test of baby and as case 3 and 4 had already tested negative before discharge, a further test was not done. We could not detect viral RNA in twenty-five breast milk samples collected from mothers positive for 
SARS-CoV-2. The placenta was not checked for vertical transmission.

\section{Discussion}

With standard infection prevention and control practices, four neonates of fifty-four COVID-19 positive mothers $(7.4 \%)$ tested positive in our study suggesting a reasonable potential of infection transmission to neonates in the developing country setting. In a large observational cohort study from New York, out of 1481 deliveries, $116(8 \%)$ mothers were COVID-19 positive ${ }^{6}$. The high percentage of COVID-19 positive mothers in our study (35.2\%) is due to fact that our hospital was declared a dedicated COVID-19 hospital in the later part of the study and only positive patients were admitted during this time. In the above study, none of the neonates had symptoms of COVID-19 and all were negative for SARS-CoV-2 at 24 hours (120), 5-7 days (82), and 14 days (72) of life. Hence, it was suggested that perinatal transmission of COVID-19 is unlikely to occur if correct hygiene precautions were undertaken, and that allowing neonates to room-in with their mothers and direct breastfeeding are safe procedures when paired with effective parental education of infant protective strategies ${ }^{6}$. However, there are many reports of neonatal COVID-19 infection from other countries such as UK, Italy and China confirming our findings ${ }^{2-5,7-9}$. Variable test positivity in neonates could be due to variable compliance to correct hygiene precautions during and immediately after birth by healthcare workers (HCWs) and parents, sample contamination, surface contamination or variable sampling technique by $\mathrm{HCWs}^{4,8}$

Similar to other reports, we found no severe clinical complications or deaths in COVID-19 positive neonates as compared to fatality rates of $4-15 \%$ in adults $^{7,12-14}$. In one case series, one out of 22 babies had mild distress and in other reports, three patients developed disseminated intravascular coagulation (DIC) possibly because of suspected sepsis ${ }^{3,4,5}$. In our study, COVID-19 babies had high respiratory rate, lower pulse oxygen saturation $(\mathrm{SpO} 2)$, low haemoglobin, high platelet count and high CRP with limited clinical relevance as none of them needed additional treatment and none of them developed respiratory failure, DIC or other complications. Other studies have also found lower haemoglobin and red blood cell counts in COVID-19 patients and it was more obvious in severe and critically ill patients $^{15,16}$. Pathophysiology of anaemia in SARSCoV-2 is still unclear but evidence suggests inhibited haematopoiesis in the bone marrow and triggered haemophagocytosis in pulmonary hilar/ mediastinal lymph nodes ${ }^{15-17}$. Variables in affected neonates also indicate similar mechanism triggering inflammation but it seems to be self-controlled without manifesting into disease.
Many theories have been postulated to explain the lower severity of COVID-19 in infants and children. In addition to absence of co-morbidities and lifestyle factors, immature inflammatory response, protective role of fetal haemoglobin against dissociation into porphyrin, and more efficient T-cells are other specific factors that might limit disease progression following SARS-CoV-2 infection in this age group $^{18}$. Disease severity in mothers or mode of delivery does not seem to correlate with infection transmission risk in neonates in this study, though sample size is not sufficient to make statistical inference. High rate of LSCS could be due to preferred approach by the obstetricians in view of the COVID pandemic or because of the fact that only high risk cases are booked here for delivery ${ }^{19}$.

Most of the studies have suggested horizontal transmission of SARS-CoV-2 in neonates but there are some case reports suggesting vertical transmission, particularly in early onset infection $3,9,20-23$. Two out-born neonates in our study had positive SARS-CoV-2 on $5^{\text {th }}$ day of life, one of whose mother tested positive before and after delivery; the other mother tested negative before and after delivery; however, the family was screened as part of contact tracing due to father's exposure to a positive case at work place, suggesting horizontal transmission.

Vertical transmission may be possible through placenta in-utero or through breast milk during the neonatal period. In a study by Patane L, et al, two cases of suspected vertical transmission of COVID19 were reported. In this study, SARS-CoV-2 RNA was found in placental tissue but no evidence of positive dots to suggest viable virus was seen in the placenta ${ }^{24}$. Evidence is still inconclusive whether this is a mere presence of genetic material or an infective virus. Dong L, et al speculated on the possibility of the maternal-fetal transmission of the virus due to the presence of virus-specific IgG and IgM antibody in a baby delivered by COVID-19 positive mother ${ }^{25}$. Caution is advised in interpreting the results as only the finding of specific $\operatorname{IgM}$ in the newborn is not enough and the overall risk of COVID-19 infection due to in-utero exposure for infants remains to be determined ${ }^{26}$. In a systemic review of $\mathrm{WHO}$, the available data were not sufficient to conclude vertical transmission of COVID-19 through breastfeeding ${ }^{27}$. In our study viral RNA was not detected in 25 breastmilk samples collected from COVID-19 positive mothers. Some studies have shown SARS-CoV-2 in faecal matter and hence the chance of incidental exposure during childbirth also cannot be ruled out $^{28}$.

In infants, the risk of COVID-19 infection is low and the infection is typically mild or asymptomatic, 
while the consequences of not breastfeeding and separation between mother and child can be significant. Hence, the WHO endorses the practice of initiation and continued breastfeeding of infants born to mothers with suspected or confirmed COVID-19 infection ${ }^{27}$. In our study, both in-born neonates were initially COVID negative but turned positive at 48-72 hours of birth with the possibility of vertical transmission or horizontal transmission either at the time of birth or during care of the baby in neonatal isolation. Vertical transmission could not be ruled out as we did not test placental tissue. Asymptomatic healthcare workers could also be a potential source of infection, as during the pandemic only symptomatic healthcare workers were tested as per our institutional protocol. Further studies to document the presence of replicative COVID-19 virus in cell culture from amniotic fluid, placenta, and breast milk and their infectivity in animal models will help in understanding possible routes of transmission in neonates.

The limitation of our study is the small number of cases. Although all neonates were tested with COVID-19 RT-PCR at least twice during the hospital stay, we primarily relied on clinical symptoms, and as repeat test was not done during follow-up, asymptomatic but infected neonates, were likely to be missed. As we did not do amniotic fluid, placental, and cord sampling, a definite route of transmission could not be determined.

This study focuses on the pattern of neonatal COVID-19 infection from India, conducted during the peak of the pandemic in a developing country setting. Neonates are also vulnerable to SARS-CoV2 infection from the community. The findings can be generalized to most of the developing countries where the pandemic is going on. Although breast milk was negative, the placenta can still be the route of transmission and further studies are needed to evaluate the same

\section{Conclusions}

With standard infection prevention and control practices, potential of infection transmission in neonates exists though they had less severe disease and needed no specific treatment except supportive care.

\section{References}

1. World Health Organization. Coronavirus disease (COVID-19) outbreak situation. Available from: https://www.who.int/emergencies/diseases /novel-coronavirus-2019. (Accessed on May 21, 2021).
2. Chen H, Guo J, Wang C, Luo F, Xuechen $\mathrm{Y}$, Zhang $\mathrm{W}$, et al. Clinical characteristics and intrauterine vertical transmission potential of COVID-19 infection in nine pregnant women: a retrospective review of medical Lancet 2020; 395(10226): 809-15. https://doi.org/10.1016/S01406736(20)303 60-3

3. Yu Y, Chen P. Coronavirus disease 2019 (COVID-19) in neonates and children from China: A Review. Frontiers in Pediatrics 2020; 8: 287.

https://doi.org/10.3389/fped.2020.00287

PMid: 32574286 PMCid: PMC7243210

4. Zeng L, Xia S, Yuan W, Yan K, Xiaou F, Shao J. et al. Neonatal early-onset infection with SARS-CoV-2 in 33 neonates born to mothers with COVID-19 in Wuhan, China. JAMA Pediatrics 2020; 174(7): 722-5. https://doi.org/10.1001/jamapediatrics.202 0.0878

PMid: 32215598 PMCid: PMC7099530

5. Zhu H, Wang L, Fang C, Peng S, Zhang L, Chang $\mathrm{G}$, et al. Clinical analysis of 10 neonates born to mothers with 2019-nCoV pneumonia. Translational Pediatrics 2020; 9(1): 51-60.

https://doi.org/10.21037/tp.2020.02.06

PMid: 32154135 PMCid: PMC7036645

6. Salvatore CM, Han JY, Acker KP, Tiwari $\mathrm{P}$, Jin J, Brundler L, et al. Neonatal management and outcomes during the COVID-19 pandemic: an observation cohort study. Lancet Child and Adolescent Health 2020; 4: 721-7.

https://doi.org/10.1016/S23524642(20)302 $35-2$

7. Chen N, Zhou M, Dong X, Qu J, Gong F, Han Y, et al. Epidemiological and clinical characteristics of 99 cases of 2019 novel coronavirus pneumonia in Wuhan, China: a descriptive study Lancet 2020; 395(10223): 507-13. https://doi.org/10.1016/S01406736(20)302 $11-7$

8. Lu Q, Shi Y. Coronavirus disease (COVID19) and neonate: What the neonatologist needs to know. Journal of Medical Virology 2020; 92(6): 564-7.

https://doi.org/10.1002/jmv.25740

PMid: 32115733 PMCid: PMC7228398 
9. Dumpa V, Kamity R, Vinci AN, Noyola E, Noor A. Neonatal coronavirus 2019 (COVID-19) infection: A case report and review of literature. Cureus 2020; 12(5): e8165.

https://doi.org/10.7759/cureus.8165

PMid: 32432015 PMCid: PMC7234017

10. Tiwari L. All India Institute Of Medical Sciences Patna Standard Operating Procedure \& Hand Book For COVID-19 Management, Version 3: 8th July 2020. Available at:

https://www.aiimspatna.org/advertisement /COVID_SOP_AIIMS_P_version3.0.pdf. (Accessed on Āpril 2, 2021).

11. Chaudhary BK. Neonatal care of babies born to suspected/ confirmed COVID mothers In Tiwari L (Ed). All India Institute Of Medical Sciences Patna Standard Operating Procedure \& Hand Book For COVID-19 Management, Version 3: 8th July 2020. Available at: https://www.aiimspatna.org/advertisement /COVID_SOP_AIIMS_P_version3.0.pdf. (Accessed on Āpril 2, 2021).

12. Huang C, Wang Y, Li X, Ren L, Zhao J, Hu $\mathrm{Y}$, et al. Clinical features of patients infected with 2019 novel coronavirus in Wuhan, China. Lancet 2020; 395(10223): 497-506.

https://doi.org/10.1016/S01406736(20)301 83-5

13. Wang $\mathrm{D}, \mathrm{Hu} \mathrm{B}, \mathrm{Hu} \mathrm{C}$, et al. Clinical characteristics of 138 hospitalized patients with 2019 Novel Coronavirus-Infected Pneumonia in Wuhan, China JAMA 2020; 323(11): 1061-9.

https://doi.org/10.1001/jama.2020.1585

PMid: 32031570 PMCid: PMC7042881

14. Yang X, Yu Y, Xu J, Shu H, Xia J, Liu H, et al. Clinical course and outcomes of critically ill patients with SARS-CoV-2 pneumonia in Wuhan, China: a singlecentred, retrospective, observational study Lancet Respiratory Medicine 2020; 8(5): 475-81.

https://doi.org/10.1016/S22132600(20)300 79-5

15. Yuan X, Huang W, Ye B, Chen C, Huang $\mathrm{R}, \mathrm{Wu} \mathrm{F}$, et al. Changes of haematological and immunological parameters in COVID19 patients. International Journal of Haematology 2020:1-7. https://doi.org/10.1007/s12185-020-

02930-w

PMid: 32656638 PMCid: PMC7354745

16. Taneri PE, Gómez-Ochoa SA, Llanaj E, Raguindin PF, Rojas LZ, Roa-Diaz ZM, et al. Anaemia and iron metabolism in COVID-19: a systematic review and metaanalysis. European Journal of Epidemiology 2020; 35: 763-73. https://doi.org/10.1007/s10654-02000678-5

PMid: 32816244 PMCid: PMC7438401

17. Prilutskiy A, Kritselis M, Shevtsov A, Yambayev I, Vadlamudi C, Zhao Q, et al. SARS-CoV-2 Infection-Associated Haemophagocytic Lymphohistiocytosis. American Journal of Clinical Pathology 2020; 154(4): 466-74.

https://doi.org/10.1093/ajcp/aqaa124

PMid: 32681166 PMCid: PMC7454285

18. Rawat M, Chandrasekharan P, Hicar MD, Lakshminrusimha S. COVID-19 in newborns and infants-low risk of severe disease: Silver lining or dark cloud? American Journal of Perinatology 2020; 37(8): 845-9.

https://doi.org/10.1055/s-0040-1710512

PMid: 32380565 PMCid: PMC7356082

19. Nayak AH, Kapote DS, Fonseca M, Chavan N, Mayekar R, Sarmalkar M, et al. Impact of the coronavirus infection in pregnancy: A preliminary study of 141 patients. Journal of Obstetrics and Gynecology India 2020; 70: 256-61. https://doi.org/10.1007/s13224-02001335-3

PMid: 32760169 PMCid: PMC7340730

20. Cook J, Harman K, Zoica B, Verma A, D'Silva P, Gupta A. Horizontal transmission of severe acute respiratory syndrome coronavirus 2 to a premature infant: multiple organ injury and association with markers of inflammation. Lancet Child and Adolescent Health 2020; 4(7): 548-51. https://doi.org/10.1016/S23524642(20)301 66-8

21. Zhu H, Wang L, Fang C, et al. Clinical analysis of 10 neonates born to mothers with 2019-nCoV pneumonia. Translational Pediatrics 2020; 9(1): 51-60.

https://doi.org/10.21037/tp.2020.02.06 PMid: 32154135 PMCid: PMC703664 
22. Chen H, Guo J, Wang C, et al. Clinical characteristics and intrauterine vertical transmission potential of COVID-19 infection in nine pregnant women: a retrospective review of medical records. Lancet. 2020; 395(10226): 80915.

https://doi.org/10.1016/S01406736(20)303 60-3

23. Yu N, Li W, Kang Q, Xiong Z, Wang S, Lin X, et al. Clinical features and obstetric and neonatal outcomes of pregnant patients with COVID-19 in Wuhan, China: a retrospective, single-centre, descriptive study. Lancet Infectious Diseases 2020; 20(5): 559-64.

https://doi.org/10.1016/S14733099(20)301 76-6

24. Patanè L, Morotti D, Giunta MR, et al. Vertical transmission of coronavirus disease 2019: severe acute respiratory syndrome coronavirus 2 RNA on the fetal side of the placenta in pregnancies with coronavirus disease 2019-positive mothers and neonates at birth. American Journal of Obstetrics and Gynecology MFM 2020; 2(3): 100145.

https://doi.org/10.1016/j.ajogmf.2020.100

145

PMid: 32427221 PMCid: PMC7233206
25. Dong L, Tian J, He S, Zhu C, Wang J, Liu $\mathrm{C}$, et al. Possible vertical transmission of SARS-CoV-2 from an infected mother to her newborn. JAMA 2020; 323(18): 18468.

https://doi.org/10.1001/jama.2020.4621

PMid: 32215581 PMCid: PMC7099527

26. Kimberlin DW, Stagno S. Can SARSCoV-2 infection be acquired in utero? More definitive evidence is needed. JAMA 2020; 323(18): 1788-9.

https://doi.org/10.1001/jama.2020.4868 PMid: 32215579

27. World Health Organization. Breastfeeding and COVID-19. Scientific Brief. https://www.who.int/newsroom/commentaries/detail/breastfeedingand-covid-19. (Accessed on August 31, 2020).

28. Vella F, Senia P, Ceccarelli M, Vitale E, Maltezou H, Taibi R, et al. Transmission mode associated with coronavirus disease 2019: a review. European Review for Medical and Pharmacological Sciences 2020; 24(14):7889-904. 